\title{
Autologous Transplantation of Adrenal Medulla Into the Caudate Nucleus: A Four Year Follow Up Study
}

\author{
E. Garcia-Flores, A. Martinez-Campos and R. Farias \\ Osler Clinic, Monterrey, Mexico
}

The objective of this study was to determine whether the associated morbidity and mortality of adrenal medulla autologous transplantation into the striatum (open transcortical procedure) justifies this as a safe and effective treatment for Parkinson's Disease (PD).

\section{METHODS}

The 4 year postoperative status was evaluated in 17 patients with PD who were recipients of adrenal medulla autologous transplants between August, 1987 and August, 1988. The results were compared with those obtained at the two year follow-up published in $1990 / 1 /$.

Two patients were lost to follow-up and two additional patients died of pneumonia (aside from the 3 deaths we reported in 1990).

The parameters evaluated included:

a) The Unified Parkinson's Disease Rating Scale (UPDRS), including: the modified Hoehn/Yahr scale, Schwab and England assessment score, mentation, activities of daily living (ADL), and motor examination;

b) Neuropsychological evaluation (12 patients);

c) Neurophysiological evaluation (10 patients);

d) Pre- and postoperative diabetes mellitus and endocrine evaluation.

Data forms were collected at baseline, and at 24 and 48 months postoperative periods. All medical complications were registered. Ten of the seventeen surviving patients had MRI of the brain postoperatively.

\section{RESULTS}

1. Two patients (9\%) showed long lasting improvement. However, we identified some characteristics that put them out of the mean group of the illness:

a) PD started at early age; 24 (B.B.) and 41 years (B.C.);

b) One of the patients was exposed to DDT (B.C.);

c) Neither of the two had received Levodopa on a regular basis.

2. A second group (23\%) showed a disability score quite similar to the preoperative level. This related to a less aggressive course of PD that we considered brought the clinical course to a "plateau".

3. The third group (68\%) showed a progressive aggravation of the symptoms, and was the depositary of most of the complications. There were three operative deaths related to the surgical procedure, two within 30 days after surgery, and one in the first 3 months. These data showed an overall operative mortality of $12 \%$. Two additional deaths occurred 18 and 36 months after the operations were performed, both of them due to pneumonia.

4. This group of operated patients presented signs of long-term deleterious effects on the regulation of the hypothalamic-hypophyseal adrenocortical axis, for example, decreased cortisol level and a two-fold incidence of diabetes mellitus after surgery $(17 \%)$. We related this to a reduction in the tolerance of stress after unilateral adrenalectomy, particularly in patients over $55 / 2 /$.

5. This group also showed signs of progressive ageing as shown by Schwab and England scores. Radiological or NMRI changes of the brain, as 
well as EEG changes, were present in ageing relatively young adults. Finally, a progressive decline of I.Q., particularly short-term memory, was seen.

These conclusions are similar to the ones reported by our group two years ago, and are in agreement with the recent report by the United Parkinson Foundation Neurotransplantation Registry /3/.

\section{REFERENCES}

1. Garcia-Flores E, Decanini HL, Flores-Salazar M, Lozano-Morales E, Zuniga C, Martinez-Campos A. Is autologous transplant of the adrenal medulla into the striatum an effective therapy for Parkinson's Disease? Prog Brain Res 1990; 82: 643-655.

2. Martinez-Campos A, Garcia-Flores E. Long and short term endocrine failure in patients with Parkinson's disease after autologous transplant of adrenal medulla into the caudate nucleus. Can J Neurol Sci 1990 17: 244 (abstr).

3. Goetz CG, Stebbins GT III, Klawans HL, Koller WC, Grossman RG, Bakay RAE, Penn RD and the United Parkinson Foundation Neural Transplantation Registry: United Parkinson Foundation Neurotransplantation Registry on adrenal medullary transplants: Presurgical, and 1 and 2-year follow up. Neuro$\log 1991 ; 41$ : 1719-1722.
TABLE

\begin{tabular}{|c|c|c|c|}
\hline \multicolumn{2}{|c|}{ Base line } & \multirow{2}{*}{$\frac{2 \text { years }}{20}$} & \multirow{2}{*}{$\frac{4 \text { years }}{17}$} \\
\hline No. of patients & 24 & & \\
\hline Female & 9 & 7 & 7 \\
\hline Male & 15 & 13 & 10 \\
\hline \multicolumn{4}{|l|}{ UPDRS } \\
\hline \multicolumn{4}{|l|}{ Mentation } \\
\hline Group I & 6.5 & $6.5(0)$ & $6.5(0)$ \\
\hline Group II & 7.25 & $7.50(-.25)$ & $7.75(-.5)$ \\
\hline Group III & 6.50 & $8.00(-.1 .5)$ & $8.75(-.2 .25)$ \\
\hline \multicolumn{4}{|l|}{$A D L$} \\
\hline Group I & 32.5 & $21.25(+11.3)$ & $20.5(+12)$ \\
\hline Group II & 23.5 & $22.5(+1.5)$ & $23.15(-0.35)$ \\
\hline Group II & 53 & $62.8(-9.8)$ & $75.6(-12.6)$ \\
\hline \multicolumn{4}{|l|}{ Motor } \\
\hline Group I & 46.5 & $30(+16.5)$ & $20(+26.5)$ \\
\hline Group II & 39.0 & $38.7(+0.3)$ & $42.5(-3.5)$ \\
\hline Group III & 40 & $48(-8)$ & $60.5(-20.5)$ \\
\hline \multicolumn{4}{|l|}{ Hoehn/Yahr } \\
\hline Group I & 3.5 & $2.1(+1.4)$ & $2.7(+0.8)$ \\
\hline Group II & 3.0 & $2.75(+0.25)$ & $3.50(-0.5)$ \\
\hline Group III & 3.5 & $3.8(-0.3)$ & $4.5(-1.0)$ \\
\hline \multicolumn{4}{|c|}{ Schwab/England } \\
\hline Group I & 40 & $80(+40)$ & $70(+30)$ \\
\hline Group II & 50 & $52.5(+2.5)$ & $50.5(+0.5)$ \\
\hline Group III & 55 & $45(-10)$ & $30(-25)$ \\
\hline \multicolumn{4}{|l|}{ I.Q. } \\
\hline Group I & 78 & $72.5(-5.5)$ & $70.5(-7.5)$ \\
\hline Group II & 102.3 & $94.3(-8)$ & $92.3(-10)$ \\
\hline Group III & 78.5 & $70.5(-8)$ & $60.6(-13.9)$ \\
\hline
\end{tabular}

UPDRS denotes Unified Parkinson's Disease Rating Scale, and ADL activities of daily living scale. Values in parentheses represent changes in the mean score as compared with the base-line scores. Negative signs indicate decline from base-line. Mentation UPDRS ranges from 0 (normal) to 16 (very abnormal) and positive signs indicate improvement, ADL ranges from 0 (normal) to 70 (very abnormal). Motor ranges from 0 (normal) to 68 (very abnormal. $\mathrm{H} / \mathrm{Y}$ stages range from 0.5 (least disabled) to 5.0 (most disabled). Schwab/England scale ranges from 100 percent (no disability) to 0 percent (extreme disability). 

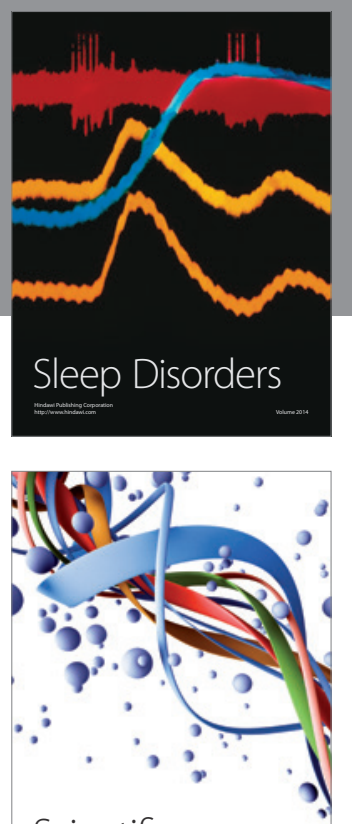

Scientifica
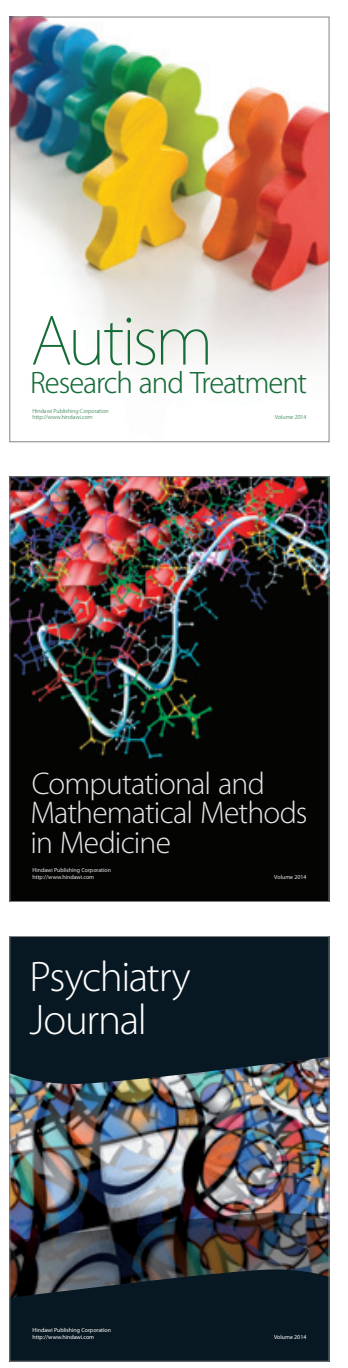
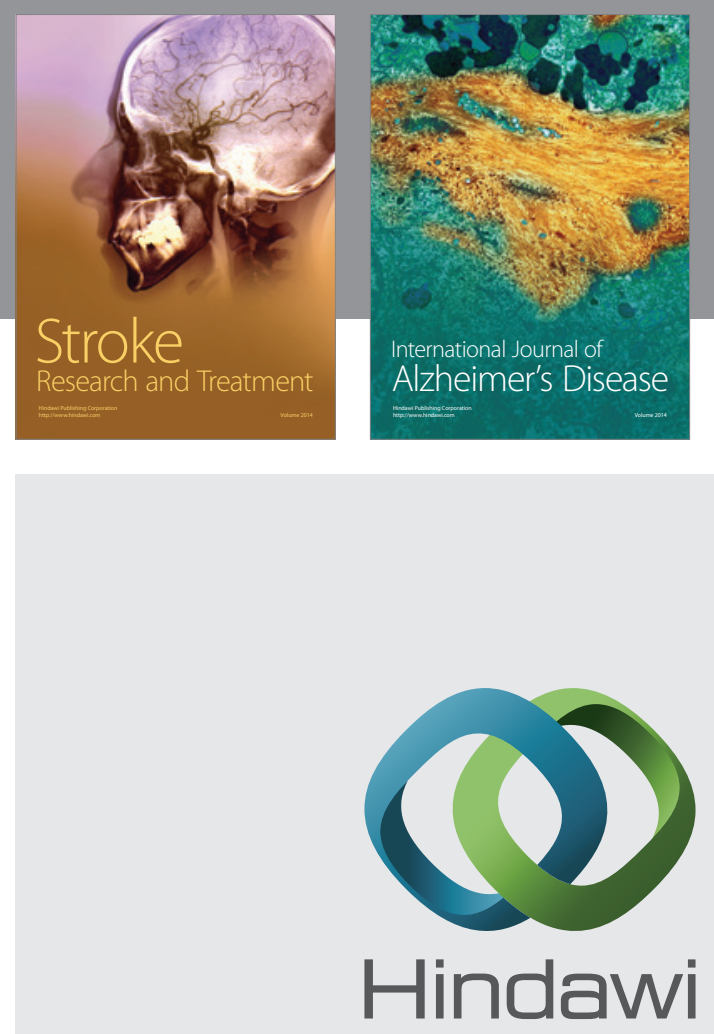

Submit your manuscripts at

http://www.hindawi.com
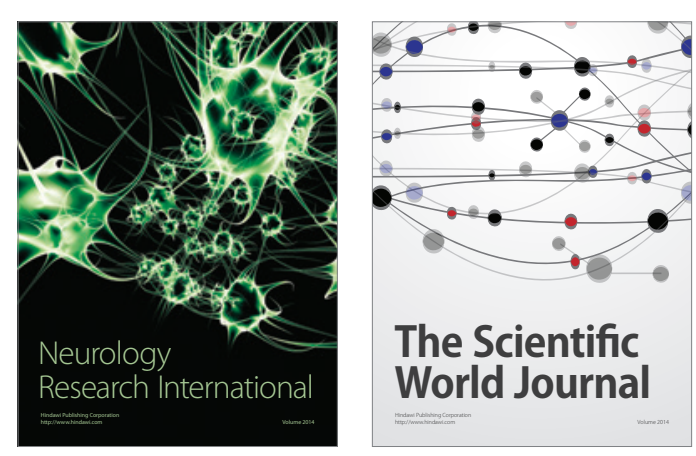

The Scientific World Journal

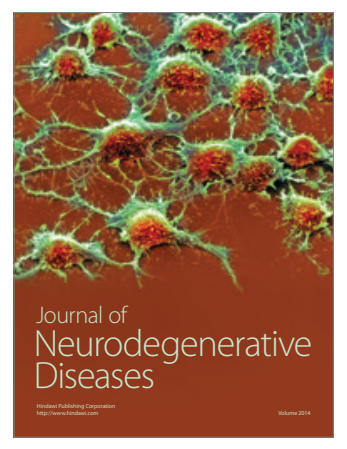

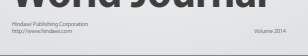

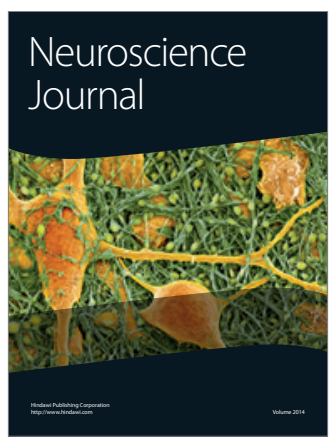

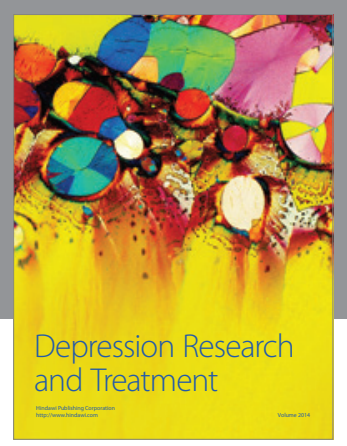
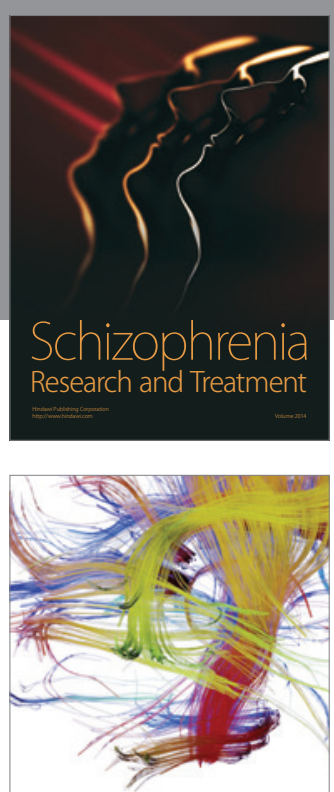

Brain Science

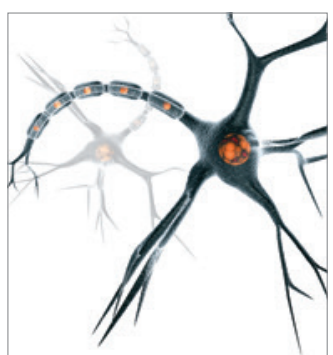

Neural Plasticity
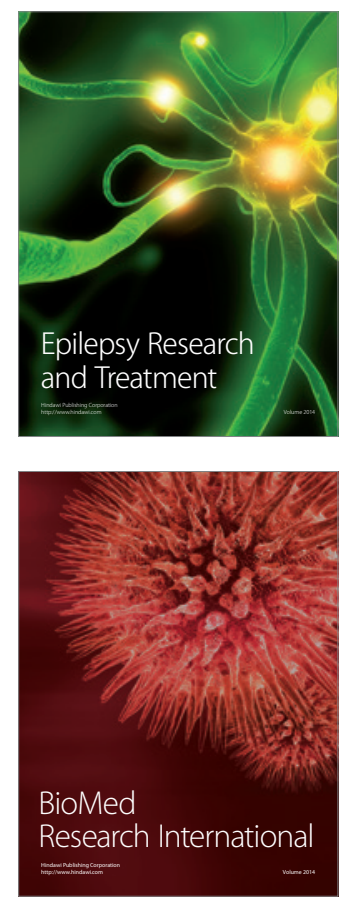

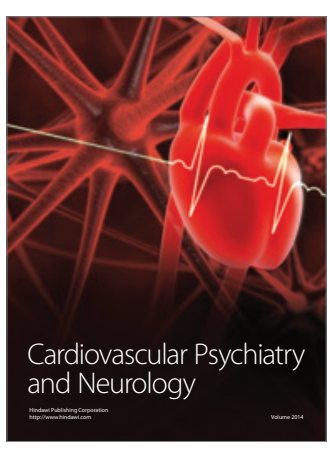

Parkinson's

Disease
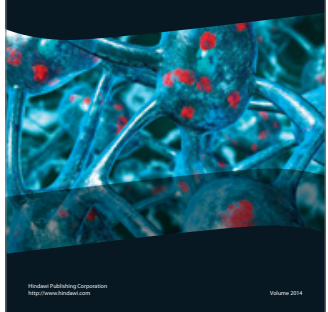